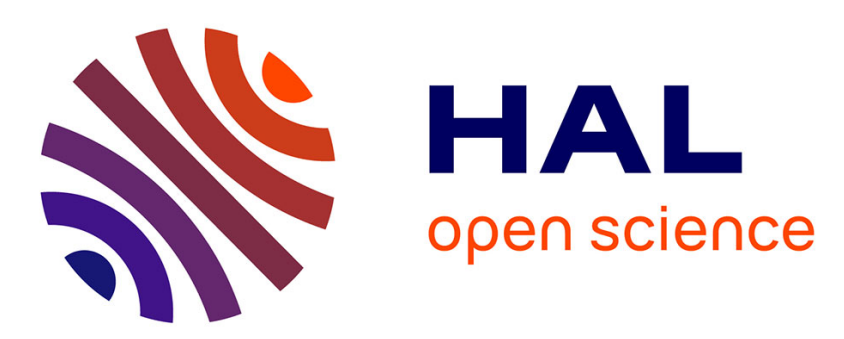

\title{
Influence of grain size and stoichiometry on the electrical behaviour of $\mathrm{YBa} 2 \mathrm{Cu} 3 \mathrm{O} 7-\delta$
}

D.S. Smith, S. Suasmoro, Christian Gault, F. Caillaud, A. Smith

\section{To cite this version:}

D.S. Smith, S. Suasmoro, Christian Gault, F. Caillaud, A. Smith. Influence of grain size and stoichiometry on the electrical behaviour of $\mathrm{YBa} 2 \mathrm{Cu} 3 \mathrm{O} 7-\delta$. Revue de Physique Appliquée, 1990, 25 (1), pp.61-66. 10.1051/rphysap:0199000250106100 . jpa-00246163

\section{HAL Id: jpa-00246163 https://hal.science/jpa-00246163}

Submitted on 1 Jan 1990

HAL is a multi-disciplinary open access archive for the deposit and dissemination of scientific research documents, whether they are published or not. The documents may come from teaching and research institutions in France or abroad, or from public or private research centers.
L'archive ouverte pluridisciplinaire HAL, est destinée au dépôt et à la diffusion de documents scientifiques de niveau recherche, publiés ou non, émanant des établissements d'enseignement et de recherche français ou étrangers, des laboratoires publics ou privés. 
Classification

Physics Abstracts

$74.40 \mathrm{~b}-81.40 \mathrm{Rs}$

\title{
Influence of grain size and stoichiometry on the electrical behaviour of $\mathrm{YBa}_{2} \mathrm{Cu}_{3} \mathrm{O}_{7-\delta}$
}

\author{
D. S. Smith, S. Suasmoro, C. Gault, F. Caillaud and A. Smith \\ Ecole Nationale Supérieure de Céramique Industrielle, 47 à 73 Avenue Albert Thomas, 87065 Limoges \\ Cedex, France
}

(Reçu le 28 mai 1989, accepté le 12 septembre 1989)

\begin{abstract}
Résumé. - Cette étude est relative au rôle de la microstructure sur les propriétés électriques de $\mathrm{YBa}_{2} \mathrm{Cu}_{3} \mathrm{O}_{7-\delta}$ polycristallin. Les données expérimentales concernent les effets de la variation de taille de grains, d'une part, et l'écart à la stœchiométrie, d'autre part, sur la densité de courant critique à champ nul, mesurée à $77 \mathrm{~K}$, et la résistivité à température ambiante. Tout d'abord, une forte décroissance de la densité de courant critique est observée lorsque la taille moyenne des grains excède $15 \mu \mathrm{m}$. Les gros grains favorisent les microfissures liées aux changements anisotropes de volume pendant le refroidissement depuis la température de frittage. Ces microfissures réduisent la section efficace du matériau capable de transporter le courant. Les mesures par ultra-sons confirment qu'il existe une augmentation de la quantité de microfissures dans les échantillons possédant de gros grains. Par ailleurs, une modification importante des propriétés électriques est observée lorsque les écarts à la stœchiométrie sont supérieurs à $0,5 \mathrm{~mol} \%$. D'autres travaux ont montré que la présence de phases minoritaires conduisent à des courants critiques plus faibles. Un écart à la stœchiométrie dans la poudre de départ favorise la formation de phases minoritaires. En conséquence, le choix d'un procédé d'élaboration de la céramique doit prendre en compte ces paramètres.
\end{abstract}

\begin{abstract}
The role of the microstructure for the electrical properties of polycrystalline $\mathrm{YBa}_{2} \mathrm{Cu}_{3} \mathrm{O}_{7-\delta}$ is examined. Experimental data are presented showing the effect of (i) variation in grain size and (ii) deviation from stoichiometry for $\mathrm{YBa}_{2} \mathrm{Cu}_{3} \mathrm{O}_{7-\delta}$ on the critical current density in «zero " field at $77 \mathrm{~K}$ and the room temperature resistivity. Firstly a strong decrease in the critical current density has been observed when an average grain size of $15 \mu \mathrm{m}$ is exceeded. Large grains promote microcracks due to anisotropic volume changes during cooling from the sintering temperature. This causes a reduction in the effective current carrying crosssection of the material. Ultrasonic measurements were used to confirm an increase in the microcrack density for large grained samples. Secondly, a significant modification of the electrical properties was achieved for deviations from stoichiometry greater than 0.5 mole \%. Previous work has shown that the presence of minor phases due to incomplete calcination or poor mixing leads to reduced critical current density. Deviations from stoichiometry of the initial powder will also promote minor phases. These two aspects must be taken into account in the choice of a suitable ceramic processing route.
\end{abstract}

\section{ntroduction.}

The electrical properties of ceramic superconductors in the $\mathrm{YBa}_{2} \mathrm{Cu}_{3} \mathrm{O}_{7-\delta}$ family are strongly influenced by the microstructure relating to the method and details of preparation. For example thin films carry critical currents greater than $10^{5}$ A.cm ${ }^{-2}$ [1] whereas bulk ceramics yield values typically in the range $10^{2}-10^{3} \mathrm{~A} . \mathrm{cm}^{-2}$. These lower critical current densities in the bulk ceramics are generally explained by the presence of weak links separating superconducting regions.
Several types of defect in the microstructure may contribute weak link behaviour. The materials are in essence 2-dimensional conductors (or superconductors) and the mismatch of grains which will occur in a microstructure with random grain orientations decreases the critical current density, $j_{\mathrm{c}}$ [2]. TEM studies have shown the presence of structural defects such as intergrowths and twinning [3], suggesting another source of weak links at the scale of a few atomic distances. In addition, pores, microcracks, and insulating minor phases will also play a signifi- 
cant role. These last three factors can be distinguished from true « weak links » since their most important effect is to reduce the effective current carrying cross-section which however also leads to a smaller critical current. The separation of the effects of the different imperfections in the ceramic microstructure is an intrigueing and technologically important problem.

In this perspective, the present paper examines the changes in the electrical properties of bulk ceramic $\mathrm{YBa}_{2} \mathrm{Cu}_{3} \mathrm{O}_{7-\delta}$ which occur for (i) variation in grain size, and (ii) deviation from stoichiometry. A simple model to facilitate interpretation of the experimental data is also presented. Another important parameter is the oxygen content of the samples. McNalford et al. [4] have shown that $j_{\mathrm{c}}$ decreases for densities greater than $92 \%$ of theoretical density which is explained by inhibited access of oxygen to the interior of the sample. The transformation from the tetragonal to the orthorhombic phase occurs during cooling from the sintering temperature and requires oxygen uptake. The samples in this study had densities in the range $85-90 \%$ of the theoretical density permitting a satisfactory oxidation. The penalty of a reduced effective cross-section due to $10 \%$ porosity should not be too severe [5].

\section{Experimental.}

1. Preparation. - Bulk ceramic samples were prepared using standard procedure. This involves grinding the stoichiometric mixture of $\mathrm{Y}_{2} \mathrm{O}_{3}, \mathrm{CuO}$, and $\mathrm{BaCO}_{3}$ powders by hand with mortar and pestle, calcination at $940^{\circ} \mathrm{C}$, and sintering of the pressed disc at $975^{\circ} \mathrm{C}$ in air. The purity of the starting powders was $99.99 \%$ or greater. X-ray diffraction measurements indicated minor quantities of $\mathrm{CuO}$ and $\mathrm{BaCuO}_{2}$ in the calcined product. The firing cycle also includes an annealing step at $600{ }^{\circ} \mathrm{C}$ followed by slow cooling $\left(1{ }^{\circ} \mathrm{C} /\right.$ minute) down to room temperature. Some of the samples were reannealed in oxygen at approximately $500{ }^{\circ} \mathrm{C}$ to promote the tetragonal to orthorhombic transformation.

Another series of samples was obtained using a powder prepared by a dissolution-recrystallization route in an organic medium. The average crystallite size of the powder was determined by Sherrer's method and is of the order of $0.1 \mu \mathrm{m}$.

2. Characterization. - Densities of sintered material were evaluated using Archimedes' principle. The microstructure was examined by scanning electron microscopy and the average grain size was estimated with Jeffries procedure. For electrical characterization samples were cut and polished in the form of thin bars, typically $1.1 \mathrm{~cm}$ long with a cross sectional area of 0.01 to $0.02 \mathrm{~cm}^{2}$. The room temperature resistivity and the current-voltage behaviour at $77 \mathrm{~K}$ in «zero » magnetic field were measured using a 4-terminal configuration. «Zero » field refers to zero applied field but includes the presence of the earth's magnetic field of approximately $0.5 \times 10^{-4} \mathrm{~T}$. Electrical contact was achieved using silver epoxy paint which yielded an electrode resistance of less than $5 \mathrm{ohms}$ reproducibly. Heating effects on the current carrying terminals were minimized by immersion of the sample in liquid nitrogen. The critical current density was evaluated using a criterion of $1 \mu \mathrm{V} / \mathrm{cm}$ between the voltage sensing electrodes.

\section{Results and discussion.}

1. POLYCRYSTALline ASPECTS IN THE ELECTRICAL BEHAVIOUR. - In common practice, the electrical behaviour of a ceramic superconductor is characterized by the critical current density at $77 \mathrm{~K}$ in «zero » field, $j_{\mathrm{c}}$, and the normal state resistivity at room temperature, $\rho_{300}$. From a technological point of view the aim is to achieve the maximum possible value of $j_{\mathrm{c}}$. This should be associated with a low value of $\rho_{300}$ since the imperfections in the ceramic which limit $j_{c}$ also yield additional resistance in the normal state. As an example, consider the introduction of a hypothetical crack into the ceramic such that the effective current carrying cross-section is reduced by a factor of 2 . Earlier work has shown that the critical current is directly proportional to the sample cross-section [6] and hence the measured critical current density will be halved while the measured resistivity doubles. However microstructural changes can be envisaged where $j_{\mathrm{c}}$ and $\rho_{300}$ are not so directly related.

(a) Normal state. - Studies of single crystals show that the resistivity in the $a-b$ plane depends linearly on the temperature which can be attributed to scattering of charge carriers by phonons [7-9]. Similar behaviour is observed for polycrystalline material [9], suggesting that the resistance to charge transfer at the grain boundaries does not influence significantly the overall character of the response in the ceramic and the dominant contribution is due to the bulk of the grains (otherwise, if the grain boundaries presented large barriers to charge transfer compared to the grains an Arrhenius type behaviour would be obtained as in, for example, zinc oxide varistors at low applied voltages). However values of $\rho_{300}$ generally situate in the range $0.9-1.0 \mathrm{~m} \Omega-\mathrm{cm}$ for the best bulk ceramics compared to $0.15 \mathrm{~m} \Omega-\mathrm{cm}$ for a single crystal ( $a-b$ plane). The discrepancy can be explained by voidage, grain misalignment, and possibly minor phases which reduce the effective current carrying cross-section without crossing a percolation threshold such that there is a change in the character of the electrical behaviour as a function of temperature. A simplified schematic and equivalent circuit is given in figure $1 \mathrm{a}$. 


\section{[a] Normal State}
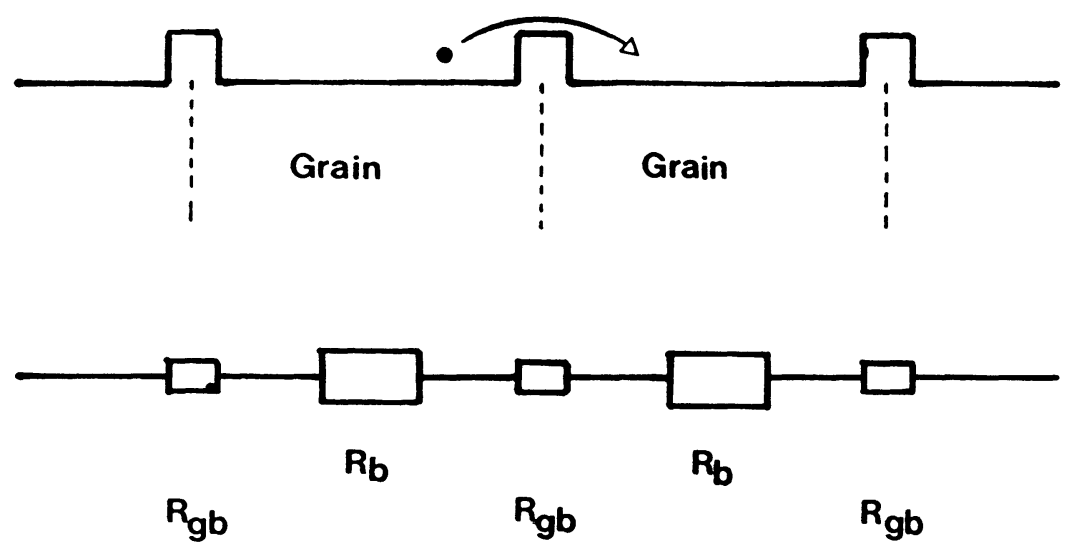

\section{Equivalent circuit}

\section{[b] Superconducting State}
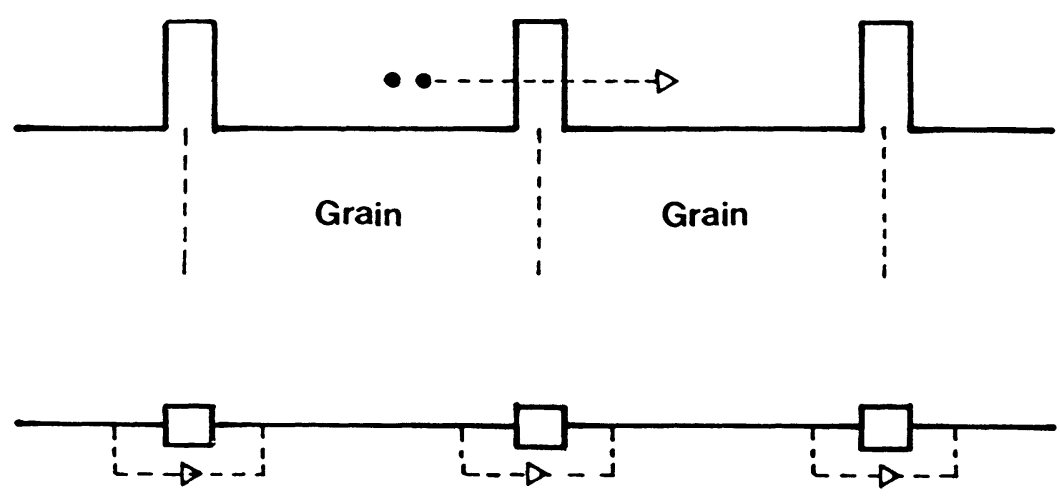

\section{Equivalent circuit}

Fig. 1. - Idealized schematic of the electrical response for polycrystalline $\mathrm{YBa}_{2} \mathrm{Cu}_{3} \mathrm{O}_{7-\delta}$.

(b) Superconducting state. - At $77 \mathrm{~K}$ the grains in polycrystalline material, in a first approximation, have zero resistance. But the grain boundaries which previously gave neglible resistance to charge transfer, now become significant barriers and dominate the electrical response by acting as weak links, figure $1 \mathrm{~b}$.

Consequently, any alterations to these barriers should have a pronounced effect on $j_{\mathrm{c}}$ without necessarily modifying $\rho_{300}$ very much. In contrast, microstructural changes such as an increase in porosi-

effective current carrying cross-section should be revealed by both $j_{c}$ and $\rho_{300}$.

2. GRAIN SIZE. - Two schools of thought exist concerning the effect of grain size on $j_{\mathrm{c}}$. The first considers that a reduction in the number of grain boundaries (hence large grains) leads to an increase in $j_{c}$ [10]. Alternatively Chiang et al. [11] have concluded from their experimental data on $\mathrm{La}_{2-x} \mathrm{Sr}_{x} \mathrm{CuO}_{4}$ that only the weakest link determines $j_{\mathrm{c}}$ and that grain size has little role. In addition to this aspect the effect of grain size for microcracking must be taken into account.

Previous work showed that the microstructure evolves as a function of sintering time by (i) grain growth, and (ii) change of grain shape from long thin rectangular shaped grains to a more rounded and equiaxed form [6]. These changes can be explained by the involvement of a liquid phase during sintering due to the presence of residual $\mathrm{CuO}$ after the calcination step.

Samples were sintered for different durations in or er o s u y e e ect o grain growt on $t$ electrical properties. The density, grain size, and room temperature resistivity $\rho_{300}$ measurements are summarized in table I. For sintering times of 20 hours and longer the density of the samples is constant within error and therefore this factor should not influence the data significantly. Reannealing the samples in oxygen leads to higher values of $j_{\mathrm{c}}$ due to an increase in oxygen content, figure 1 . For both air annealed and oxygen reannealed samples the increase of grain size has little apparent effect on $j_{\mathrm{c}}$ and $\rho_{300}$ for sintering times up to 45 hours. If any 
trends exist they can be explained by a slight increase in density between 10 hours and 20 hours sintering or they are obscured by the scatter of the data. However samples which are sintered for 60 hours exhibit a pronounced drop in $j_{c}$ with a parallel increase in $\rho_{300}$. Furthermore the air annealed and oxygen reannealed samples have similar values of $j_{\mathrm{c}}$ suggesting the oxygen content is no longer different between the two sets of samples.

Table I. - Density, grain size, and room temperature resistivity measurements for $\mathrm{YBa}_{2} \mathrm{Cu}_{3} \mathrm{O}_{7-\delta}$ sintered at $975{ }^{\circ} \mathrm{C}$ with different durations.

$\begin{array}{ccccc}\begin{array}{c}\text { Sintering } \\ \text { time } \\ \text { (hours) }\end{array} & \begin{array}{c}\text { \%of } \\ \text { theoretical } \\ \text { density }\end{array} & \begin{array}{c}\text { Grain } \\ \text { size } \\ (\mu \mathrm{m})\end{array} & \begin{array}{c}\text { Resistivity } \\ \text { at } 300 \mathrm{~K} \\ (\mathrm{~m} \Omega . \mathrm{cm}) \\ \text { Air }\left(^{*}\right)\end{array} & \mathrm{O}_{2}\left(^{* *}\right) \\ \overline{10} & - & - & - & - \\ 20 & 86 & 7 & 1.0 & 0.9 \\ 30 & 90 & 8 & 1.0 & 0.9 \\ 45 & 90 & 11 & 0.9 & 0.8 \\ 60 & 90 & 13 & 0.8 & 0.9 \\ & 90 & 15 & 1.3 & 1.3-4.8\end{array}$

$\left(^{*}\right)$ annealed in air.

$(* *)$ reannealed in oxygen.

The simplest explanation is that microcracking has occurred. This yields a geometrical change on the microscopic scale in the sample such that there is a reduction in the effective current carrying crosssection. The presence of microcracks would also facilitate the movement of oxygen through the ceramic during annealing. Consequently reannealing in oxygen no longer increases the oxygen content.

In order to confirm this hypothesis ultrasonic non destructive tests were made on samples (discs, $10 \mathrm{~mm}$ in diameter and $3 \mathrm{~mm}$ thick) sintered for the same durations. The velocities $v_{\mathrm{L}}, v_{\mathrm{T}}$, and the attenuations $\alpha_{\mathrm{L}}, \alpha_{\mathrm{T}}$ of $10 \mathrm{MHz}$ longitudinal and transverse ultrasonic waves were measured using a pulse-echo technique. For a microcracked ceramic a decrease in $v_{\mathrm{L}}$ and $v_{\mathrm{T}}$ due to the deterioration of the elastic properties and an increase in $\alpha_{\mathrm{L}}, \alpha_{\mathrm{T}}$ due to multiple scattering are expected as discussed elsewhere [12]. The results show such effects as a function of sintering time, figure 2. Though the sample density is greater for longer sintering times which should lead to higher ultrasonic velocities, a decrease is observed for both $v_{\mathrm{L}}$ and $v_{\mathrm{T}}$. Furthermore, whereas samples sintered for 20 hours did not exhibit any propagation difficulties, there was such an increase in attenuation for longer sintering times that no echo was observed for longitudinal waves in 45 and 60 hour samples, and similarly for transverse waves in 30, 45, and 60 hour samples. Figure 3

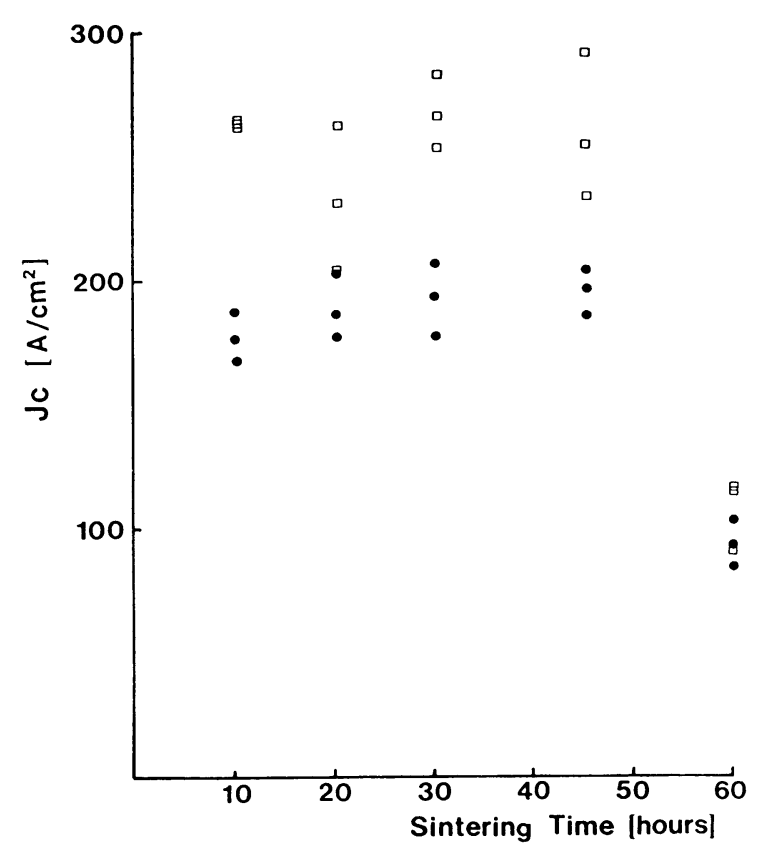

Fig. 2. - Critical current density measured at $77 \mathrm{~K}$ in «zero" field versus sintering time of polycrystalline $\mathrm{YBa}_{2} \mathrm{Cu}_{3} \mathrm{O}_{7-\delta}$. The dots $(\bullet)$ represent samples which have been annealed in air. The squares $(\square)$ represent samples which have been reannealed in oxygen at $500{ }^{\circ} \mathrm{C}$.

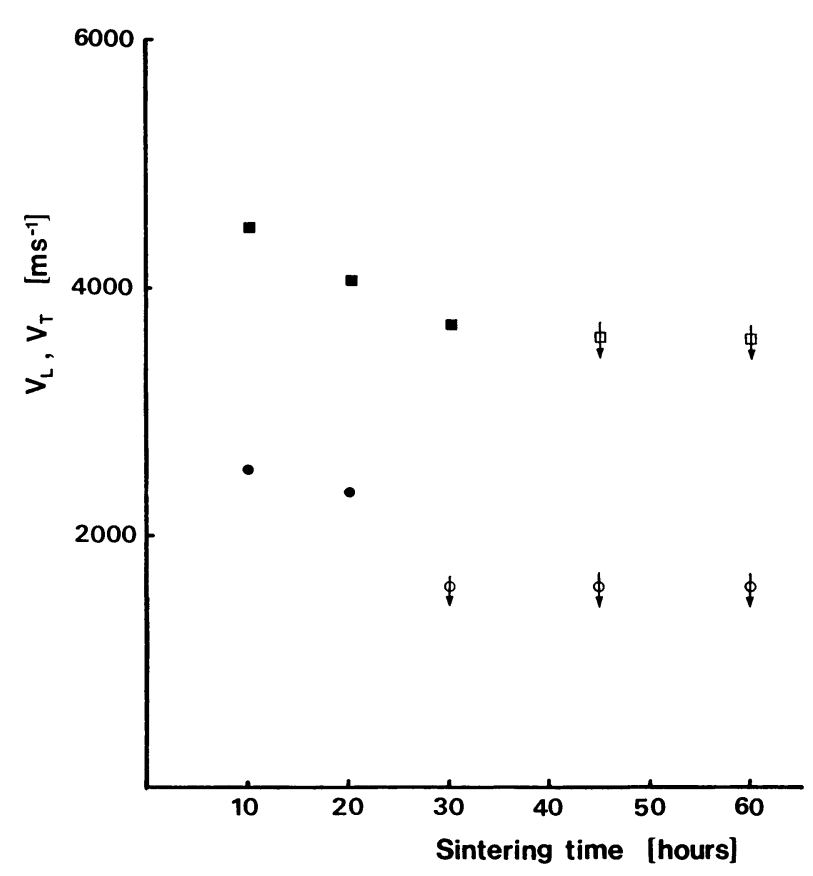

Fig. 3. - The velocities of longitudinal (squares) and transverse (dots) ultrasonic waves as a function of sintering time for oxygen reannealed polycrystalline $\mathrm{YBa}_{2} \mathrm{Cu}_{3} \mathrm{O}_{7-\delta}$. The arrows indicate samples where the signal was too attenuated for measurement.

shows that in the extreme case of 60 hours sintering this microcracking occurs mainly along the grain boundaries. 
The origin of these microcracks can be sought in terms of anisotropic volume changes of the grains during cooling from the sintering temperature giving rise to internal stresses. Such an effect due to anisotropic thermal expansion is well known in single phase polycrystalline ceramics and depends on the difference of thermal expansion coefficients along the crystal axes and on the grain size [13]. In this case the microcracks follow the grain boundaries as can be observed in figure 4. $\mathrm{YBa}_{2} \mathrm{Cu}_{3} \mathrm{O}_{7-\delta}$ exhibits anisotropic thermal expansion but another source of microcracking may be significant due to oxygen uptake associated with the tetragonal to orthorhombic phase transformation. This is also accompanied by anisotropic lattice parameter changes. A change in the oxygen content at $500{ }^{\circ} \mathrm{C}$ from $7-\delta=6.37$ to $7-\delta=6.92$ yields $\Delta a=-0.98 \%, \Delta b=+0.49 \%$, and $\Delta c=-0.53 \%$ [14].

The ultrasonic tests suggest that microcracking has even occurred for samples sintered for 10 hours and 20 hours. Calculation of Young's modulus gave

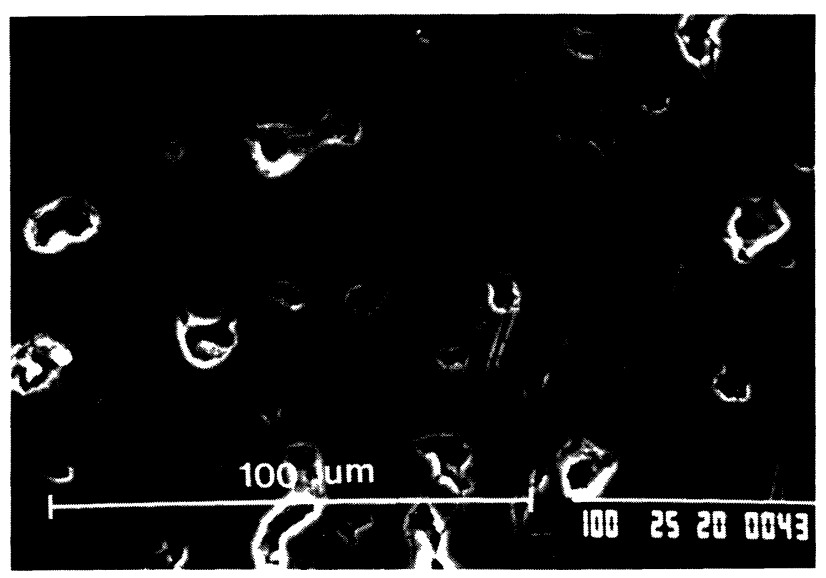

a)

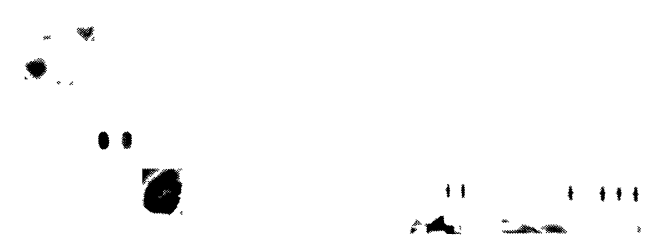

b)

Fig. 4. - Micrographs of $\mathrm{YBa}_{2} \mathrm{Cu}_{3} \mathrm{O}_{7-\delta}$ sintered for (a) 20 hours and (b) 60 hours. values of $100 \mathrm{GPa}$ and $85 \mathrm{GPa}$ respectively. This can be compared to $130 \mathrm{GPa}$ obtained by extrapolation of data by $\mathrm{McN}$. Alford et al. [15] for a porosity of $10 \%$. Recent work by Shaw et al. [16] reports an onset of microcracking in polycrystalline $\mathrm{YBa}_{2} \mathrm{Cu}_{3} \mathrm{O}_{7-\delta}$ for grain sizes of 1-2 $\mu \mathrm{m}$. An important question is whether a number of microcracks can be tolerated in the ceramic before significant effect on the electrical response. It can be noted that a significant drop in $j_{\mathrm{c}}$ did not occur until a sintering time of 45 hours was exceeded. Alternatively an unidentified phenomenon may be masking the effect of the microcracks.

3. DeViation fRom STOICHIOMETRY. - Previous work has shown that the presence of minor phases due to incomplete calcination or poor mixing leads to reduced $j_{\mathrm{c}}$ [6]. Deviations from stoichiometry will also promote minor phases. We wished to explore (i) the level of stoichiometry which must be maintained before significant change in the electrical properties, and (ii) the effect on $\rho_{300}$.

In order to achieve an accurate control of the composition a chemically prepared powder was used. After sintering for 10 hours in air at $970{ }^{\circ} \mathrm{C}$ stochiometric $\mathrm{YBa}_{2} \mathrm{Cu}_{3} \mathrm{O}_{7-\delta}$ yielded values of approximately $100 \mathrm{~A} \cdot \mathrm{cm}^{-2}$. However microcracking

Table II. - Room temperature resistivity and critical current density at $77 \mathrm{~K}$ measurements for off stoichiometric compositions of $\mathrm{YBa}_{2} \mathrm{Cu}_{3} \mathrm{O}_{7-\delta}$. The deviation is an excess in each case.

\begin{tabular}{ccc}
\hline $\begin{array}{c}\mathrm{CuO} \\
\text { deviation (mol \%) }\end{array}$ & $\begin{array}{c}\rho_{300} \\
(\mathrm{~m} \Omega . \mathrm{cm})\end{array}$ & $\begin{array}{c}j_{\mathrm{c}} \\
\left(\mathrm{A} / \mathrm{cm}^{2}\right)\end{array}$ \\
\hline 0.2 & 2.0 & 101 \\
0.5 & 2.9 & 77 \\
1.0 & 4.1 & 63 \\
\hline
\end{tabular}

$\mathrm{BaO}$

deviation (mol \%)

\begin{tabular}{crr}
\hline 0.5 & $\dot{2}$ & \\
1.0 & 26.3 & 60 \\
& & 6 \\
\hline $\mathrm{Y}_{2} \mathrm{O}_{3}$ & & \\
\hline deviation $(\mathrm{mol} \mathrm{\% )}$ & & \\
\hline 0.2 & 1.6 & 137 \\
0.5 & 2.4 & 31 \\
1.0 & 6.7 & 40 \\
\hline
\end{tabular}


was thought to have occurred because large grains upto $80 \mu \mathrm{m}$ long were observed by microscopy and reannealing in oxygen-did not result in a significant change in $j_{\mathrm{c}}$. If the composition deviates by $0.5 \%$ or greater $j_{\mathrm{c}}$ drops significantly in value, table II. Generally it is accompanied by a similar increase in $\rho_{300}$. This suggests that the minor phases which have been promoted are so insulating that their presence simply leads to a reduction in the effective current carrying cross-section. It can be noted that the sample containing 1 mole $\%$ excess $\mathrm{Y}_{2} \mathrm{O}_{3}$ exhibited widely dispersed spots of the green phase $\left(\mathrm{Y}_{2} \mathrm{BaCuO}_{5}\right)$ visible to the naked eye.

\section{Conclusions.}

The role of the microstructure for the electrical properties of polycrystalline $\mathrm{YBa}_{2} \mathrm{Cu}_{3} \mathrm{O}_{7-\delta}$ has been examined with respect to grain size, minor phases, and oxygen content. If a parameter participates in the control of the effective current carrying crosssection of the material then both $j_{c}$ and $\rho_{300}$ are influenced. Thus large grain sizes, which induce microcracks due to anisotropic volume changes on cooling from the sintering temperature, result in a decrease in $j_{c}$ with a parallel increase of $\rho_{300}$. A significant increase in the microcrack density was confirmed by ultrasonic measurements for larger grained samples. An additional effect of microcracking is to facilitate movement of oxygen through the ceramic and hence the oxygen uptake which is associated with the tetragonal to orthorhombic phase transformation. The presence of minor phases due to deviation from stoichiometry (on a macroscopic or local scale) can also result in a reduction of the effective current carrying cross-section.

\section{References}

[1] Gyorgy E. M., Grader G. S., Johnson D. W., Jr., Feldman L. C., MurPhy D. W. and Rhodes W. W., Hasard R. E., Manlliewich P. M. and Skoopol W. J., Appl. Phys. Lett. 52 (1988) 328.

[2] Ekin J. W., Braginski A. I., Panson A. J., JenocKo M. A., Capone D. W., Zaluzec N. J., FLANDERMEYER B., DE LIMA O. F., HONG M., Kwo J., Liou S. H., J. Appl. Phys. 62 (1987) 4821.

[3] Michel C., Hervieu M., Raveau B., Proceedings of Journées d'Etudes à l'ISMRA - Caen (France), 96 (September 1988).

[4] McN. Alford N., Clegg W. J., Harmer M. A., Birchall J. D., Kendall K. and Jones D. H. Nature 332, 6159 (1988) 58-59.

[5] Bernard H., Thesis, Grenoble (1980).

[6] Smith D. S. Suasmoro and Baumard J. F., Proceedings of Journées d'Etudes à l'ISMRA, Caen (France) 43 (September 1988).

[7] Kitazawa K., Takagi H., Kishio K., Hasegawa T., UChida S., TAJIMA S., TANAKA S. and Fueki K., Physica C 153-155 (1988) 9-14.
[8] ONG N., Wang Z. Z., Hagen S., Jing T. W., Clayhold J. and Horvath J., Physica C 153155 (1988) 1072-1077.

[9] Gurvitch M. and Fiory A. T., Phys. Rev. Lett. 59 (1987) 1337-1340.

[10] Ekin J. W., Adv. Ceram. Mater. 2 (1987) 586.

[11] Rosko A., Chiang Y. M., Moodera J. S. and Rudman D. A., Ceramic Superconductors II Research Update, published by the American Ceramic Society, Ed. M. F. Yan (1988), p. 308.

[12] Gault C., Proceedings of the MRS Fall Meeting, Boston (November 1988).

[13] Tvergaard V. and Hutchinson J. W., J. Am. Ceram. Soc. 71 (1988) 157.

[14] O'Bryan H. M. and Gallagher P. K., Ceramic Superconductors II, published by the American Ceramic Society, Ed. M. F. Yan (1988) p. 89.

[15] McN.Alford N., Birchall J. D., ClegG W. J., Harmer M. A. and Kendall K., J. Mat. Sci. 23 (1988) 761-768.

[16] Shaw T. M., Shinde S. L., Dimos D., Cook R. F., DunCOMBe P. R. and Kroll C., J. Mater. Res. 4 (1989) 248. 